\title{
Ecosystem Services (ES) and their Modeling and Evaluation
}

\author{
Omar Alsharef \\ phd candidate \\ DOI: 10.29322/IJSRP.11.06.2021.p11454 \\ http://dx.doi.org/10.29322/IJSRP.11.06.2021.p11454
}

\begin{abstract}
Sustainable development is a harmonious relationship between ecology and economy, in order to preserve the natural wealth of our planet for future generations. Sustainable development can be achieved only when the ecological, social and economic aspects of life gain equal importance and attention in all areas of human work and activities, and thus, or even in the first place, in food production. In all spheres of human activities, and especially in the field of environmental protection, there is a growing awareness of the limitations that our planet has and the need to reduce human impact to the least dangerous, tolerant and sustainable level.

It can be said that sustainable development is a general direction, an aspiration to create a better world, balancing social, economic and environmental factors. Thus, the principle of sustainable development is an attempt to determine the obligations and rules that ensure that the needs and desires of today's people are not met to the detriment of the vital interests of future generations. Therefore, the moral requirements implied by the principle of sustainable development are the norms of fair treatment of people in the future. This formal principle also raises the normative question of what are the values that make human life quality and meaningful, and thus critically analyzes the very concept of sustainability.

Economic instruments are one of the categories used in the implementation of environmental policy. These instruments can also be used as a ground for other environmental policy instruments or can be complementary to them (eg various regulations and agreements on mutual cooperation in any field).
\end{abstract}

Index Terms- protected areas, biodiversity, sustainability, heritage site.

\section{INTRODUCTION}

$\mathrm{N}$ atural resource management refers to the management of resources such as land, water, plants and animals, with special emphasis on how management affects the quality of life for both present and future generations. Natural resource management deals with managing the way people and the natural environment communicate. It includes land use planning, water management, biodiversity conservation and sustainability. Natural resource management recognizes that people and livelihoods rely on the health and productivity of our environment and their actions as managers play a role in maintaining this health and productivity. Natural resource management is also in line with the concept of sustainable development, with a particular focus on understanding resources and ecology. Environmental management is similar to natural resource management. Components of a healthy environment, such as clean air and water, are considered public goods and the absence of rivalry is excluded. Thus, it is up to the public sector to maintain the provision of these goods and services. More recently, countries have gone in the direction of incorporating environmental costs through marketbased mechanisms to ensure long-term environmental stability, in other words, to ensure sustainable development.

When evaluating ES services, it is important to consider all values and all stakeholders over a long period of time. For an individual, unsustainable extractive use (such as tree felling) is often immediate and highly profitable for the resource owner, while costs (such as soil erosion, poorer water quality, and carbon emissions) are largely borne by more people. longer term. In the end, all the hidden costs of environmental degradation represent a great cost to society as a whole. Similarly, valuing only the benefits of ecotourism ignores the benefits that local communities have succeeded or failed to achieve.

It is therefore important that the valuation we receive from ES services takes into account the views and values of all stakeholders. In addition, valuation should not be viewed unilaterally and in the short term, but long-term implications should also be considered because some values are short-term, while others exist for years, decades and even centuries. So the assessment of ES services can be very complex. It is also important to recognize that in addition to the benefits of ES services, there are also costs associated with the implementation of management activities. Like benefits, costs can vary from global to local, from international to local communities. Therefore, when estimating the total value of benefits from ES services, it is necessary to think about all costs. Today, there is a growing interest in measuring, modeling and evaluating ecosystem services (ES), all those benefits that ecosystems provide to humans. This phenomenon has resulted in the development of a number of ES assessment tools in recent years. Choosing the right tool for measuring and modeling ES can be a challenge. This part of the paper deals with a review of information and guidance on existing tools that can be used to measure or model ES, which can be applied to biodiversity and nature conservation, including key biodiversity areas, World Natural Heritage sites and protected areas. These guidelines build on existing reviews of ES assessment tools, but have an explicit focus on ES assessment for sites that are important for biodiversity and nature conservation. 


\section{KEY TERMS OF FOR ES ASSESSMENTS}

We will list a few terms that are used when evaluating the EC. Key areas of biodiversity (KBA - Key Biodiversity Area) are places that significantly contribute to the global survival of biodiversity. World Natural Heritage (WHS - World Heritage Site) are natural features, formations and areas that are considered "outstanding universal values" due to their exceptional qualities and therefore deserve special protection. Protected areas (PA Protected Areas) are clearly identified and defined geographical areas, which are managed in an efficient manner, which are protected by legal or other means in order to achieve long-term nature conservation with associated ecosystem services and cultural values. ES information provided by KBA, WHS, and PA can be useful for a number of reasons, including increased support to protect the multiple benefits provided by such sites, information to help manage management decisions, ensure equity in resource use and benefit-sharing, and enable impact assessment management or policy changes to the ES provided by such sites. In this part of the paper, we will summarize a number of possible reasons for ES assessment and identify tools that can be used for such purposes.

Three viewed tools, EST, TESSA and PA-BAT, are PDF documents that users can view ES estimates step by step. The EST is a guidance document consisting of steps with practical sheets for conducting a qualitative and / or quantitative assessment of the $\mathrm{EC}$, indicators, advice on relevant issues and a set of tools, methods and models that can be applied. PA-BAT is a rapid and standardized assessment of the perception of various factors on the benefits of ES from protected and other areas. TESSA is a PDF manual that provides accessible guidelines and inexpensive methods for assessing the benefits that people have by nature in specific locations. The other six reviewed tools are computerbased modeling tools. ARIES and MIMES are modeling platforms, which can contain ES scenarios, spatial and economic assessments and integrate different environmental and economic models for understanding and visualizing ES values.

Selecting the appropriate tool requires identifying the specific question being asked, what types of results are required, and considering practical factors such as the level of expertise, available time, and data required to apply any of the available tools. Although each tool is different, they all provide an opportunity to answer ecosystem-related questions and support policy management and decision-making.

Key areas of biodiversity, protected areas and natural world heritage can contribute to the EU in a variety of ways. The ES may exist locally within the site (eg pollination services originating from the same location) or the ES may be produced elsewhere, but may also exist at a location that provides ecosystem services to users (eg a river that springs elsewhere, and flows through the location). These ESs can be received as benefits by people staying in, near or away from the location. ES assessments should take into account these different ways in which sites contribute to the provision of ES services as site management can improve or degrade ES or change the approach of ES by users.

KBA, PA and WHS characterize important values of ES conservation. In many cases, preserving the value of biodiversity in these locations will contribute to or improve the provision of ES services. It is important to understand that a particular ES (e.g. unsustainable fishing) could conflict with conservation objectives.
In these cases, trade-offs may be needed between the ongoing delivery of environmental objectives and the conservation of biological diversity. Well-preserved habitats can also contribute to the surrounding ES areas, for example, by serving as a habitat for fishing nurseries or as a source of genetic diversity. Therefore, KBA, PA and WHS play a key role in ensuring the long-term delivery of ES services. Their importance will grow only as the natural ecosystems in the surrounding areas are increasingly lost or decayed (eg by turning uncultivated land into agricultural land). Being able to understand and measure ES services can support their definition and management and contribute to ensuring a better balance in the provision of ES services.

Up to today, more than $15,000 \mathrm{KBAs}$ have been identified worldwide and appear in a global database of key areas of biodiversity. The identification and effective protection of these sites is crucial for the conservation of biodiversity globally (Edgar et al., 2008). KBA are not necessarily protected areas. The criteria for characterizing $\mathrm{KK}+\mathrm{BA}$ are limited to elements of biodiversity, including species, ecosystems, biological processes, and ecological integrity. However, the Global Standard for the Identification of Key Biodiversity Areas (IUCN, 2016) recommends that documentation for each site include information on the ES. This documentation is basic and qualitative. It contains a list of ES provided by the location, the reason why the location is especially important for those services and users. Measuring, modeling and evaluating the ECs provided by CBAs can improve our understanding of the benefits that these sites provide to human well-being and strengthen environmental protection and sustainable management.

\section{WHS - WORLD HERITAGE SITE}

World Natural Heritage (WHS) are cultural monuments, archaeological sites or natural features, formations and areas that due to their exceptional qualities are considered "outstanding universal value" and therefore deserve special protection (UNESCO, World Heritage Center, 2017).

Natural WHS are those that are recognized for their outstanding natural values and include sites such as the Serengeti Reserve in East Africa, Yellowstone National Park, USA and the Great Barrier Reef, Australia. To be listed as a World Natural and Cultural Heritage Site, a site must meet at least one of ten criteria (six criteria apply to cultural heritage and four to natural heritage), as well as integrity, protection and management standards. The vast majority of natural WHS and many cultural sites are protected areas with types and categories of management that vary by location. As of April 2018, there were 35 mixed (both cultural and natural) and 206 natural WHS globally.

Although they represent only about $0.1 \%$ of the total number of protected areas globally, natural WHS cover 294 million hectares and make up about $8 \%$ of the land area and $6 \%$ of marine protected areas (Osipova et al., 2017). WHS by definition contain globally significant cultural and / or natural values. In addition, they provide important ES services (Osipova et al., 2017). Like the KBA and Protected Areas (PAs), natural WHS contribute to food and water supply, and provide many other benefits, such as tourist opportunities and the preservation of places of cultural and spiritual value. Since the main goal of WHS is to protect their values, some activities, such as hunting and 
fishing, may be banned, so the delivery of some ES services, especially the use of some resources, may not be allowed within WHS. Protected areas (PAs) are clearly defined geographical areas, identified, dedicated and managed, by legal or other effective means, in order to achieve long-term nature conservation with associated ecosystem services and cultural values (Dudley, 2008). Protected areas include those areas where human presence or exploitation of resources is limited. The definition, which is widely accepted in regional and global frameworks, was given by the International Union for Conservation of Nature (IUCN) in its guidelines for the categorization of protected areas. The definition reads: "A protected area is a clearly defined geographical area, recognized, dedicated and managed, through legal or other effective means, in order to achieve long-term nature conservation with associated ecosystem services and cultural values." (World Database Protected Areas, 2016).

The goal of establishing protected areas is to preserve biodiversity and provide ways to measure the progress of such conservation. Protected areas usually include zoning that is important for specific types of conservation, such as bird habitats and endemic areas, plant diversity centers. Likewise, a protected area or an entire network of protected areas may be in a larger geographical area called a terrestrial or moral ecoregion or a crisis ecoregion. Protected areas can cover a wide range of management types. The range of natural resources that can protect any protected area is huge. Protected areas are, in addition to the protection and preservation of flora and fauna, important for the preservation of sites of cultural importance and significant reserves of natural resources. Although many protected areas are designated for their conservation value, PAs also have a role to play in preserving other important benefits through the provision of a wide range of ES services.

As of 2016 , just under $15 \%$ of the world's inland and inland waters, $12.7 \%$ of coastal and marine areas under national jurisdiction, and about $4 \%$ of the global ocean are covered by PA (UNEP-VCMC \& IUCN, 2016). In addition to conserving biodiversity and providing important recreational, tourist and other cultural services to ecosystems, well-protected protected areas can ensure water quality and, in some situations, increase available water, increase the resilience of vulnerable human communities in the face of natural disasters and promote health. and the well-being of the people (Stolton \& Dudley, 2010). Protected areas support food security by serving as nurseries and seed sources, increasing fish stocks and providing the possibility of plant pollination, as well as other EC services that support agriculture, aquaculture and forestry.

Understanding PA-related ECs in terms of social and economic values can increase support for their designation and inform about efforts to preserve and manage these sites for multiple benefits. Not all areas of nature importance are managed by protected areas that are nationally or internationally designated. Territories, sacred sites, protected areas under water and military grounds for some people can provide effective conservation of biodiversity without the necessary conservation as a primary goal. Such management regimes are referred to as "other effective spatial conservation measures" (OECM).

Preserved ecosystems open opportunities for many activities such as organic agricultural production, controlled use of renewable resources (water, land, wild species), development of ecotourism. Assumptions for the development of local communities are based primarily on education and support of the local population to implement projects important for preserving the environment, natural values and resources, as well as the traditional way of life with the gradual improvement of socioeconomic living conditions.

Protected areas provide a wide range of social, environmental and economic benefits to people and communities around the world. They apply an approach to nature conservation and related cultural resources by local communities, peoples, governments and other non-governmental organizations. Protected areas are vital and a response to some of the most important challenges including food and water safety, human health and well-being, disaster risk reduction and climate change. As the world continues to grow rapidly, the pressure on ecosystems and natural resources is intensifying. Protected areas, when they are regulated, when they are adequately managed and when they are built into the development strategies of the state, then they can provide solutions based on nature as an integral part of sustainable development.

KBA, WHS and PA are similar in that they are all important for the preservation or protection of places of important natural or cultural value. The species, ecosystems and genetic diversity found in these sites also provide benefits to humans in the form of food, water, energy, basic materials and cultural benefits. (Larsen et al., 2012; Osipova et al., 2014; Neugarten et al. , 2016; Ivanić et al., 2017; Mandle et al., 2017).

The type of location may have implications for its management; in the case of KBA, their identification does not imply any particular management system and is not linked to the legal status of the site. Less than $20 \%$ of the KBA is fully protected, and the average protected area coverage of each KBA is $46 \%$. PAs are formally designated sites managed by governments, local communities, private individuals or funds or other formal resource managers in combination with nature protection, recreation, cultural heritage or other purposes. For natural WHS, adequate protection and management are part of the conditions for entry on the World Heritage List and that is why most of them are officially marked as protected areas, but their categories and types of management vary.

The ES assessment can be used to establish a line to monitor changes over time or to enable the assessment of the consequences of management decisions or policy changes regarding the delivery of ES services. It can also be used as additional evidence in applications for accreditation or certification systems, such as the IUCN Green List of Protected Areas (IUCN and VCPA, 2018), which seeks to promote management efficiency in protected areas and highlights ES services. EC information may also support the development of compensation mechanisms for landowners or owners' rights to implement management practices that support conservation outcomes or new sources of site protection funding. The EC information provided by these sites may also demonstrate their importance in achieving the international value of conservation objectives, such as the UN Convention on Biological Diversity, on land / water protection, which lists "areas of particular importance for biodiversity and ecosystem services". Finally, these data can provide information on how these sites contribute to achieving the goals of the 2030 Agenda for Sustainable Development, as, for 
example, highlighted in the "Policy for the Integration of Sustainable Perspectives into the World Heritage Convention Processes" (UNESCO , 2015).

In general, the evaluation of ES services by one or more sites is valuable when there is a need for further understanding of what the benefits of ES services are, when there are clear objectives for evaluation and when there is a clear plan on how to use the results to support site conservation or management. It may not make sense to undertake an in-depth assessment of ES services if, for example, they would affect scarce resources or other needs such as conservation activities, site management and biodiversity assessment, or if they would not provide clear added value to site management. The monetary valuation of the EC can sometimes conflict with conservation objectives, for example, if the economic values associated with conservation are not as high as alternative land uses in the short term. (Schroter et al., 2014).

Certain ES services (such as cultural heritage) are difficult to assess in monetary terms and can be better assessed using non- monetary measures. It is important to keep these risks and limitations in mind and to be strategically determined when and how to evaluate ES services. It is especially important to identify situations where conservation strategies and arguments based on biodiversity or other cultural or social values may be more effective than assessing economic values. The scope of work can provide a broader picture of the full range of services provided by ES sites to users at the local, regional, national and global levels. Although only some of the ES services can be selected for further assessment, the scope helps to ensure that all benefits are identified and recorded. It can also help draw public attention to benefits that could become more important in the future, for example due to climate change or resource depletion.

\section{AUTHORS}

First Author - Omar Alsharef, phd candidate 